DOI: $10.20472 / S S .2017 .6 .1 .002$

\title{
EVALUATION OF NATIONAL POLICY TOWARD PROVIDING LOW COST HOUSING IN MALAYSIA
}

\section{BAHARE FALLAHI}

\begin{abstract}
:
Providing housing for the low income group (LIG) is one of the current challenges of most developing worlds and it is supposing to be, permanent problem in some of these countries. This research evaluates the Malaysian housing policies and programs on its particular implementation and how the practicality feature of such policies develop considerably the housing affordability and convenience to the widely held of the LIG in the Malaysia. The study will be conducted through the review prior research. Its goal is review housing policy in Malaysia for low income group because plans and policies of housing adoption of practical and all comprehensive role of the government, afford institutional support for an efficient housing delivery to the low income group.
\end{abstract}

\section{Keywords:}

Housing, Policy of Housing for the Low Income, Malaysia

JEL Classification: Z18, Z18

\section{Authors:}

BAHARE FALLAHI, university putra Malaysia, Malaysia, Email: fallahi.bahare@yahoo.com

\section{Citation:}

BAHARE FALLAHI (2017). Evaluation of National Policy toward Providing Low Cost Housing in Malaysia. International Journal of Social Sciences, Vol. VI(1), pp. 9-19., 10.20472/SS.2017.6.1.002 


\section{Introduction}

The prominence of accommodation in the economic and social improvement of a country cannot be over emphasized. Housing is the important component in the generation of economic development and improvement. The state of accommodation has had affirmative influence on the development and growth of the world. The challenge of the policy of housing in the developing world was to confirm that basic housing needs are met and at a reasonable price to the most of the people (Harris and Arku, 2007). Nevertheless, at the same time, accommodation challenges in developing world have risen by reason of rapid population growing and urbanization. Consequently, these countries face incredible pressure to afford accommodation specifically decent and reasonably priced for the low income group (LIG). Therefore, there are numerous particularly amongst the low income group without acceptable and affordable accommodation for now and in the future. As expected, these dynamics have need of a policy structure and organized mechanism that emphasis on evaluating the housing supply to deal with the growing demand on sustainable foundation. These are the concerns a supportable policy of housing be going to eliminate now and in the comer for the poor people in all countries (Abdullahi and Aziz, 2011).

The policy of housing literature strongly highlighting the significant role played by the governments and states in Asia countries in overall and Malaysia in particular (Doling,1999; Agus,2002). Although the priority afforded to meeting LIG accommodation some researchers claimed that Malaysia is lagging behind the achievement logged, for example, in Singapore, South Korea and Hong Kong (Salleh and Lee,1997; Agus,2002).

This is because in Malaysia, capitals are entrusted to proportionate with the predominant expectations and the interposition has been narrowly concentrated. Consequently, to recognize the level attained through its neighbors, the Malaysian government, at the beginning of" second Malaysia National Development Plan", has gone into corporation by the private sector in combination with market in low cost accommodation(DrakakisSmith,1977). To improve private segment developer's performance, some motivation and rules have being introduced. The reasons offered contain earlier development endorsements, relaxed planning and subtraction standards and licensing processes. On the other hand, the principles the developers are estimated to approbate contain mixed development to contain 30\% low-cost part, "minimum design standards and ceiling price of low-cost house". The government has expanded corporation with the private segment developers in housing delivery to house the low income group after four decades. The implementation so far has been commendable and illustrations that the private segment developers involvement has fostered the improvement of low-cost accommodation delivery in the country (Jamaluddin, 2005). .Consequently, the private segment has reached domination over the state, as the main producers with state duty start to reduce in the "supply of the LIG housing" (Abdullahi and Aziz, 2011). This research emphasis to literature 
on the extent the policy of housing has being sustainable in housing the LIG in the Malaysia. The research main sets out the background to the study and followed by an indication of policy of housing in Malaysia and low-cost housing program in Malaysia. The research highlights the policy of housing in Malaysia in attaining accommodation the LIG. The study will be conducted through the review prior research. Its goal is review housing policy in Malaysia for low income group because plans and policies of housing adoption of practical and all comprehensive role of the government, afford institutional support for an efficient housing delivery to the low income group. The study concludes by evaluating the significant role played through the Malaysian government in supporting the sustainability of the country's LIG accommodation by private segment involvement.

\section{Backgrounds of Housing Policies in the World}

Policy of housing documents in recent years in the world endorse that planners, policy makers, and governors have to increase accommodation accessibility for high risk individuals such as women and disabled as heads of households, which can be reflected in gender equivalence in strategies, policies and projects as "sustainable human settlements" improvement.

"On December 1948, the general assembly of the United Nations adopted and proclaimed the Universal Declaration of Human Rights (Bakhtyar et al., 2013).

Everyone, as a member of society, has the right to social security and is entitled to realization, through national effort and international co-operation and in accordance with the organization and resources of each state, of the economic, social and cultural rights indispensable for his dignity and the free development of his personality (Assembly, 1948). . Housing rights are unmistakably part of international human rights law (Bakhtyar et al., 2013). The right to adequate housing is embedded in the Universal Declaration of Human Rights (1948) and major international human rights treaties such as the International Covenant on Economic, Social and Cultural Rights".

The second United Nations Session on Human Settlements (Habitat II)(Ofori,1999). Held on 3-14 June 1996 in Istanbul, Turkey, set out significant changes in the approach to the improvement of social settlements in an urbanizing world. "The Habitat Agenda", the main document approved through the 171 UN member states in Istanbul, be aware of that suitable accommodation is an important human right. In this session, states reconfirmed that suitable housing is for all and confirmed sustainable human settlements, involvement, gender equivalence, financing accommodation, enablement and human settlements, worldwide collaboration for assisting poor persons (Ofori, 1999). Five years after "Habitat II, the General Assembly of the United Nations" held a specific conference to assessment and values performance of the "Habitat Agenda worldwide under the name Istanbul +5 . "The negotiations concentrated on some of the central outputs offered through the "Habitat secretariat for the Istanbul+5 exercise, namely: a declaration on the norms of good urban governance (Bakhtyar et al.,2013); a World Charter of Local Self- Government and; a declaration on secure tenure". UN members improved a rights-based approach to the 
Habitat Agenda and emphasized concerns for instance "females and land inheritance, slum upgrading and alternatives to forced evictions". This negotiation assisted defines a deliberative procedure on the way to the improvement of a normative agenda for safety of tenure. Participants urged "Habitat" to apply the primary procedure for "Istanbul+5 "to improve the draft proclamation on secure tenure (Bakhtyar et al.,2013).

In the literature review of the research, it is set up that new complications in accommodation came about because many households in Asia, Latin America, Africa and even in developed countries, have no availability to credit for constructing or purchasing an accommodation. Also, lack of availability to loans or mortgages "forces families to make do with inadequate resources, to live and work in multi-functional spaces combining makeshift shacks, partly finished rooms, and temporary partitions for walls (Duncan, 2008). The disability of many poor households to availability credit or loans is often viewed as an indication of greater principal obstacle of poverty, low incomes and joblessness in the country. Availability to formal funding, considered interval from average family salary levels, is a significant determining factor of accommodation situations (Duncan, 2008). Literature presents that financing organizations favor families through above-average salaries, employed in the formal part, and where the head of families is man. Even accommodation finance organizations aimed at helping low-income households have often been difficult to get to the majority of the poor persons (Bakhtyar et al., 2013).

\section{Overview of Malaysia Housing Policy}

There are 3 basic racial religious groups in Malaysia. Consequently, the accommodation industry has to take into concern all these part in the improvement of national housing and policy. The accommodation and housing pattern has been considerable due to their economic proceedings of these ethnic groups (Tan, 2011). For instance, in the past Chinese has been conquered commercial and business industry and they lives in town region. Also, Malay group living in rural region and has been dominated agricultural activities. Whereas Indian group work in palm oil estate and rubber. "In order to get rid of these unbalance in term of economic of these 3 ethnic group, the government has come out with one solution by introducing New Economic Policy (NEP) in year 1970 to change the stereotype."

The purpose why NEP was presented to" foster national unity and nation-building" via the deracination of poverty regardless of race, and the restructuring of community to remove the proof of identity of race through economic occupation and geographic position. Government has encouraged Malay persons to mobility to urban parts as part of" NEP strategy" to construct a new Malay commercial society in urban region (Tan, 2011). Though, as a result of the rise rate of Malay person's mobility's to urban regions in 1980's, the request for reasonable shelter also indications a significant demand growing. However a severe scarcity in reasonable shelter has risen. In general, there are 2 alternative for the state to support their resident in accommodation providing and one of them is allocating shelter specially to families persons are not capable to afford themselves in the broad market and one more one is to interfere in the functioning of the market in order to make it more likely to achieve the shelter needs of all families (Abdul-Aziz and Jahn Kassim,2011). 
Consequently, in the efforts to decrease accommodation problem for Malaysian resident specifically persons low income groups, the government has regulated housing plans and policies to make certain that all have the access to suitable accommodation. The key objective of policy of housing in most states was once basically to afford more houses.

This was reaction to a shortage of market driven provide on a condition of socially perceived enormous scale shelter need (Tan, 2011). A part from that, the overview and the establishing of housing programs for a country have another goal. Mat and Omar (2002), argued policy of housing is important because of :

a. To attain the optimum used of current resources.

b. To make certain the community can owned a shelter.

c. Gives guild line on new place.

d. To make assured special set of community can owned shelter such as elderly resident.

e. Steering the government and local establishments to make available fair accommodation distribution.

A National Housing Policy (NHP) is required to afford the trend and foundation for the policing and improvement of the housing segment by all related ministries, sections and organizations at the federal, state and local stages along with the private segment. In consequence, Tan, 2011, evaluated the housing policy prepared by Malaysian administration is to present:

"First Malaysian Plan (1966-1970) and Second Malaysian Plan (1971-1975): Diversity of plans

designs to help well-being of all Malaysian irrespective of ethnic background by provided that enhanced and better quality of housing, community amenities, wellbeing and other facilities. "Third Malaysian Plan (1976-1980):" To eliminate poverty and reorganize the society "Fourth Malaysian Plan (1981-1985):" The extension of former program and policy. "Fifth Malaysian Plan (1986-1990):" Housing policies are being carry out in "the context of human settlement concept". Here, the social amenities are put emphasis on rather than the establishment of basic infrastructural amenities. "Sixth Malaysian Plan (1991-1995):" Home owning within several income set is put emphasis on.

"Seventh Malaysian Plan (1996-2000): overview of low-medium cost housing. According to Residential Property Stock Report", the housing price can be classify into "low-cost housing (below RM42,000), low-medium cost housing (RM 42,000-RM 60,000), medium cost housing (RM 60,001-Rm 100,000) and high-cost housing (RM 100,001)".

"Eight Malaysian Plan": Main concern is continuous to be given to the improvement of lowand low-medium cost shelters. Private and public segment were collaborating with each other to meet shelter demand. "Ninth Malaysian Plan (2006-2010)": make certain low and low-medium income set will have the access to suitable, quality and reasonably priced shelter

"National policy in tenth plan" highlighting to make sure access to "quality and affordable housing, (this term referred to the low-cost houses) meeting the needs of a growing 
population by matching demand and supply for reasonable housing and promoting an efficient and sustainable housing industry"(Suflan and Ibrahim,2011). Besides, in order to "raising living standard of low-income households" and "improving rural basic infrastructure" there are some phases in tenth program:

i) To increase tenure by providing that 44,000 units of existing low-cost shelters for sale or rent by the "Kuala Lumpur City Hall (DBKL) and the National Housing Department (JPN)".

(ii) Providing 50,000 units of new units for the poor people in urban area by 2012. The fund will be used for main repair and maintenance works for instance the substitution of lifts and water tanks.

iv) Provided that financial support for example low-interest loans for the low-income households who are not receivers of or do not purchasing public low-cost shelters (Idrus and $\mathrm{Ho}, 2008$ ).

\section{Low Cost of Housing in Malaysia}

Low cost housing improvement in Malaysia is carrying out through both the public and private segments. The government's obligation to low cost housing in progress for the duration of the First Malaysia Plan whereas the private segment's participation was presented in the Third Malaysia policy when the government recognized the requirement and significance of the role of the private segment in confirming an suitable supply of low cost housing for the people. The significance of the private segment's role and function has been developing through the years, principally with the privatization plans carry out through the government for the improvement of the country as a whole (Idrus and Ho,2008).

Additionally, the concern of low cost housing improvement not only includes physical and environmental characteristics but moreover takes place the human context. This will too to develop the quality of life of the inhabitants and the surrounding communal along with to improve environment. The urban regions are a significant emphasis where a "total of 51,800 units of low cost flats were built in year 2005 in large cities ". Different policies had been assumed to evaluate concerns for the lower income people. Amongst the policies were the public segment role, shelter finance for informal part, open registration for low cost shelter, increasing low cost housing fund, rental for the poor area in urban region, foundation of subtraction grant, accommodation for workers, housing policies for government personnel, planning standards and persistent investigation and improvement in housing (Omar,2008).

\section{Private Sector}

Private segment housing contains of private developers, co-operative people and persons or groups of persons. "Private housing developers are actively involved in the production of high, medium and low-cost housing. They are governed by the Housing Developers (control and Licensing Act) 1966 (Amendment, 1988) and the Housing Developers' Regulation (Control and Licensing) 1989. This legislation requires them to obtain licenses, advertising and sales permits from the Ministry of Housing and Local Government before 
undertaking any housing project. According to the Housing Developer's (Control and Licencing) Act 1966, housing developers are defined as business developing and partly providing moneys for purchasing, more than four units of housing accommodation which will be or are erected by such development". To one side from private developers, private institutes are also involved in the providing of housing in Malaysia. But more in recent times, the role of the private developer was highlighted. The government had given private developers the duty of providing accommodation for the middle and higher-income people, recently they have constantly been reminded of their community duty to assisting the government attain its home-owning democracy objective. Private segment involvement has improved since the Fourth Malaysia Plan, when the government pursued the Collaboration of private developers in the establishment of low cost shelter. Specially, the government has made it obligatory for developers to build at least $30 \%$ low cost accommodations in housing plan.

\section{Public Sector}

Under public segment, the public low-cost housing policies are carry out by the state and federal governments with the management and monitoring of the "Ministry of Housing and Local Government". The governments are involved in the carrying out of

i) "Public Low Cost Housing Programmes" containing of public low cost housing, location and facilities systems and the housing loan system

ii) "Housing in Land and Regional Development Authority area"

iii) "Government and Institutional Quarters"

iv) "State Economic Development Corporation"

The federal government provides mortgages to the state governments to perform the planes by the" Ministry of Housing and Local Government". "The State Economic Development Corporation (SEDC) and the Urban Development Authority (UDA)" as well play significant roles in the afford of all kinds of shelters in their respective states principally in the urban regions. The supplies of housing in rural regions, principally in the regional improvement regions, are undertaken through the "respective Regional development Authorities (RDA)". "Nevertheless, RDAs have extent their parts to urban regions such as the case of" PERDA (the Penang Regional Development Authority) which is undertaking a joint venture development to create a mammoth township which will eventually link Butterworth and Bukit Mertajam into a major urban conurbation(Idrus and Ho,2008).'

\section{The policy of low cost housing in Malaysia}

The federal government's planes through regard to low cost shelter via the private segment can be presented as follows:

\section{i) $30 \%$ Low Cost Component}

The planes requirement all private housing developers of projects beyond a certain threshold to build at least $30 \%$ low cost accommodation units. Minimum size of improvement which must afford the low cost section varies among states, each taking into account demand (or the lack of it) along with shortage of land in main urban regions. 


\section{ii) RM25 000 Selling Price Ceiling}

Accommodations built should be sold at a 25000 selling price ceiling. This price has been a contentious matter for the reason that the cost of construction is more than selling price.

\section{iii) RM750 Household Income}

Consumers of the low cost shelters must have family income not more than RM 750 per month. About $60 \%$ or urban families in 1980 in Malaysia fell in this income set (ie income fewer than or the same to RM750). The wages level in Malaysia has however increased by about $3.1 \%$ per annum amongst 1970 to 1990 and the current labour deficiency in all segments of the economy has make certain that salaries continue to enjoy an upgrade tendency

\section{v) Minimum Design Standards}

The program specifies that each low cost shelter must have a minimum built-up space of including 2 bedrooms, a kitchen, a living room, and a bathroom. The house have any type such as flats,terrace or detached houses. In general, developers must select for high density improvements (for example flats or cluster shelters) in order to attain economist of measure or to decline the quantity of land used for the low cost element even though federal planes do not determine congestion standards, the upper limit is usually bound by a steep escalation in housing price for buildings overhead five storey because of extra requests for lifts and fire-fighting.

In an attempt to develop the quality of accommodation and to accommodate residential preferences, diverse states have initiated phases to contain some 3 bedroom units in the low-cost project (Idrus and Ho, 2008).

\section{Implementation of Housing Policy in Malaysia toward Low Cost of Housing}

Under the "Eighth Malaysia Plan (2001-2005)" 86.4 per cent of low cost shelters through 200,513 dwelling completed. Of this whole, 103,219 dwelling or 51.5 per cent was built through the public segment containing the "State Economic Development Corporations". To make certain an suitable afford of low-cost shelters for the low-income people, any mixed-development plans embark on through private sectors continuous to be conducted via the 30 per cent low-cost shelter program requirement (Omar,2008).

As per for the "Ninth Malaysia Plan (2006-2010)", the Government will continue to build low cost shelters to make sure suitable shelters for the low-income people including 24,757 units of accommodations. As well, 43,800 units of dwelling for rental along with for sale will be built to meet the estimated rise in demand from the low-income people. "The National Housing Department" is cooperating narrowly by state governments to make certain that these dwellings are constructed in appropriate places and providing through suitable public services (Omar, 2008).

"The Ninth Malaysia Plan (9MP)" gave special consideration to low-cost dwelling. The general implementation of dwellings constructed under the low-cost shelter classification 
is incentive through 200,513 dwelling finished or $86.4 \%$ of the target. Also, 103,219 dwelling or $51.5 \%$ were built through the public segment containing state economic improvement corporations (Bakhtyar et al., 2013). To make certain a suitable afford of lowcost dwellings, any mixed-improvement plans embark on via private sectors are essential to allocate a minimum of $30 \%$ to low-cost accommodation (Bakhtyar et al., 2012).

During the 9 plane, under the "Public Low-Cost Housing Program (PLHP)" for the low income people, a total of 27,006 low-cost dwellings were built under 70 plans. These plans were applied by state governments by mortgages providing through the "Federal Government" and principally focused in small towns and sub-urban regions. These dwellings were sold to eligible consumers. Eligible consumers registered under the electronic open registration system administered by the "respective state governments". The Policy "Perumahan Rakyat Bersepadu (PPRB) was employed for the resettlement of squatters" in towns and cities. Under this plane, 37,241 low-cost dwellings were built and rented out to those eligible. Out of this number of housings, 24,654 dwellings were constructed in "Wilayah Persekutuan Kuala Lumpu" whereas 12,587 dwellings are in other main cities through the Malaysia. However it is too terrible because the $10^{\text {th }}$ Malaysia Plan is only focused about 78,000 provide housing when Malaysia is facing more than $1,300,000$ persons under the poverty (Bakhtyar et al., 2013).

\section{Recommendations}

In the federal state, the requirement for policy of housing is very fundamental for long term housing policies for the Malaysia. It is in line through state strategies to become advanced country by the year 2020 . By the widespread national policy of housing, the government can evaluate and observer not only structure of low medium cost shelter but besides further types. Suitable policies and planes can be assessed since this features shortage in progress program document.

To make certain the developers to build more low cost accommodations, the motivation given to low housing for example tax assistance, earlier approval, etc. should be comprehensive to low cost housing additionally. The government as well should establish the suitable quota of low cost housing to be constructed through housing developers.

\section{Conclusions}

In reply to the prosperous realization of prompt economic development, the policy of housing in Malaysia has confirmed its capability in replying to prompt populace growth, urbanization and growing abundance, particularly by meeting the accommodation needs of low income group. Moreover, Housing development is dispersion from the capital city to other regions of the state. As a matter of fact the policy of government is tending to attaining developed "nation status in 2020". Subsequent upon this, every one of her residents is expected to be accommodated in a appropriate house with the appropriate facilities.

They have gone a long way in their accommodation improvement strategy. The corporation of the private and public segment has made accommodation for the persons realistic. The policy of housing is in line with government schedule "Adequate shelter for all". The main 
objective of policy of housing is to make sure that all her inhabitants, particularly the lowincome people, have access to suitable accommodation. It is the government eliminates to supply accommodations for the low income group by assisting private segment.

\section{References}

Abdul-Aziz, A.-R. and P. Jahn Kassim (2011). "Objectives, Success and Failure Factors of Housing PublicPrivate Partnerships in Malaysia." Habitat International 35(1): 150-157. https://doi.org/10.1016/j.habitatint.2010.06.005

Abdullahi, B. C. and W. N. A. W. A. Aziz (2011). "Pragmatic Housing Policy in the Quest for Low-Income Group Housing Delivery in Malaysia." Journal of Design and Built Environment 8: 21-38.

Agus, M. (2002). Asian Housing Policy: Similarities and Differences. IN AGUS, MR, DOLING, J. \& LEE, D.(Eds.) Housing Systems in South and East Asia, New York, Palgrave Macmillan. https://doi.org/10.1057/9781403919809_1

Agus, M. (2002). Malaysia in MR Agus, J. Doling and DS Lee (ed) Housing Policy Systems in South and East Asia, New York: Palgrave Macmillan. https://doi.org/10.1057/9781403919809_7

Assembly, U. G. (1948). "Universal Declaration of Human Rights." Retrieved February 22: 2010.

BAKHTYAR, B., et al. (2013). "Housing for Poor People: A Review on Low Cost Housing Process in Malaysia." WSEAS Transactions on Environment \& Development 9(2).

Bakhtyar, B., et al. (2012). "Affordable Quality Housing for Urban Low Income Earners in Malaysia." WSEAS Press. https://doi.org/10.2139/ssrn.2184629

Doling, J. (1999). "Housing Policies and the Little Tigers: How Do They Compare with other Industrialised Countries?" Housing Studies 14(2): 229-250. https://doi.org/10.1080/02673039982939

Drakakis-Smith, D. (1977). "Housing the Urban Ppoor in West Malaysia: The Role of the Private Sector*." Habitat International 2(5): 571-584. https://doi.org/10.1016/0197-3975(77)90029-7

Duncan, J. (2008). Causes of Inadequate Housing in Latin America and the Caribbean, Habitat for Humanity International.

Harris, R. and G. Arku (2007). "The Rise of Housing in International Development: The Effect of Eeconomic Discourse." Habitat International 31(1): 1-11. https://doi.org/10.1016/j.habitatint.2005.10.004

Idrus, N. and C. S. Ho (2008). "Affordable and Quality Housing through the Low Cost Housing Provision in Malaysia."

Jamaluddin, Z. (2005). Privatisation of Squatters Resettlement, UUM Press.

Mat, R. and R. Omar (2002). Demographic Trends in Malaysia with Special Focus on Women. 20th Population Census Conference.

Ofori, G. (1999). Satisfying the Customer by Changing Production Patterns to Realise Sustainable Construction. Proceedings, Joint Triennial Symposium of CIB Commissions W65 and.

Omar, D. B. (2008). "Communal Living Environment in Low Cost Housing Development in Malaysia." Asian Social Science 4(10): P98.

Omar, D. B. (2008). "Communal Living Environment in Low Cost Housing Development in Malaysia." Asian Social Science 4(10): P98. 
Salleh, G. and L. M. Lee (1997). Low Cost Housing in Malaysia, Utusan Publications \& Distributors.

Suflan, A. and A. Ibrahim (2011). "Equitable distribution of low-cost houses in Malaysia: constraints and challenges." International Journal of Economic and Management 5(1): 251-265.

Tan, T. H. (2011). "Measuring the Willingness to Pay for Houses in a Sustainable Neighborhood." 